\title{
FACTORS AFFECTING THE ESTABLISHMENT OF RYEGRASS SEEDLINGS IN SOLDIER FLY-INFESTED LAND
}

\author{
G. M. DIXON and R. H. DAvisON
}

Ruukura Agricultural Research Centre, Hamilton

\section{Abstract}

Soldier fly, Inopus rubriceps (Macquart), larvae suck nutrients from the roots of ryegrass, 'reducing root growth, tiller and foliage production, and probably plant survival. Accurate placement of insecticide with the seed killed larvae, and enhanced establishment of the seedlings. The use of minimum cultivation, paraquat, and fertilizer sown with the seed, all made larvae move on to the rows of new seedlings 'thereby improving the efficiency of the insecticide and establishment of the seedlings. This was associated with increased root weights and pasture production.

These techniques warrant consideration as alternatives to full surface cultivation and should readily fit into farm undersowing programmes.

\section{INTRODUCTION}

LARVAE OF soldier fly (Inopus rubriceps (Macquart)) suck sap from the roots of plants and this results in a loss of ryegrass that is often associated with an increase in the clover and weed components of the sward. To offset this effect, many farmers in soldier fly-infested areas are adopting cultivation practices (either grass to grass or via cropping) or undersowing damaged pasture during autumn.

Cultivation techniques as a means of controlling soldier fly and renovating pasture have been evaluated in terms of effectiveness and reliability (Wilcocks and Hewitt, 197 1; Cumberland et al., 1973, 1974; Dixon, 1974). A limited amount of research (Cumberland et al., 1973; Dixoa, 1974), as well as farmer observation, suggest that the effect of undersowing, if 'any, is often shost-term, not persisting beyond the summer months.

Certain systemic insecticides have been shown to be active against soldier fly larvae (Mackay et al., 1974; Dixon et al., 1974; Dixon, 1974), and are currently widely used for the pro\&e\&ion of crops at risk. In pasture high rates of insecticide have to be broadcast in order to achieve a reasonable and consistent kill of larvae. This is both expensive and undesirable because these insecticides reduce populations of such non-target organisms as earthworms and birds. There is less difference between high and 
TABLE 1: THE EFFECTIVENESS OF CARBOFURAN WHEN APPLIED AT DIFFERENT RATES AND BY DIFFERENT METHODS

(Ranges are \% mortalities; data from six sites)

\begin{tabular}{lllccc}
\hline & & & & High Rate* & Low Rate* \\
Broadcast & $\ldots$ & $\ldots .$. & $\ldots$ & $57-93$ & $0-61$ \\
Undersown & $\ldots .$. & $34-82$ & $28-79$ \\
\hline
\end{tabular}

*High rate, $4.5 \mathrm{~kg}$ a.i./ha. Low rate, $1.75 \mathrm{~kg}$ a.i./ha.

low rates when they are undersown (Table 1) probably because larvae are killed in the zone into which the insecticide is placed but not in between these zones. There is only slight lateral movement of insecticides (I. Graham-Bryce, pers. comm.),

This paper considers the effects of soldier fly on rycgress seedlings and illustrates ways in which the effectiveness of undersowing both seed and insecticide can be improved.

\section{EFFECT OF SOLDIER FLY LARVAE ON RYEGRASS SEEDLINGS}

A study of the effect of soldier fly larvae on ryegrass seedlings was carried out over the autumn and winter in pots in a glasshouse. $0.05 \mathrm{~g}$ of seed of each of the four ryegrass varieties', 'Grasslands Ruanui' perennial ryegrass, 'Grasslands Ariki' ryegrass, 'Grasslands Manawa' short-rotation ryegrass, and 'Grasslands Tama' Westerwolds ryegrass, were sown into $17.8 \mathrm{~cm}$ diameter posts containing sterilized loam into which varying numbers of soldier fly larvae had been placed.

Assessments were made of root (dry weights), plant establishment and survival, tiller production, foliage production, and larval survival.

\section{ROOT WEIGHT}

Root weight decreaesd niarkedly as the number of soldier fly larvae increased (Fig. 1). In the absence of larvae, Manawa and Tama had heavier root systems $(\mathrm{P}<0.01)$ than Ariki and Ruanui but, because Manawa and Tama suffered more severely $(P<0.05)$, all varieties had similar root weights at high infestation levels.

\section{Plant emergence and Survivit}

The presence of very high numbers of larvae had no effect upon the number of ryegrass plants emerging. After three months, 


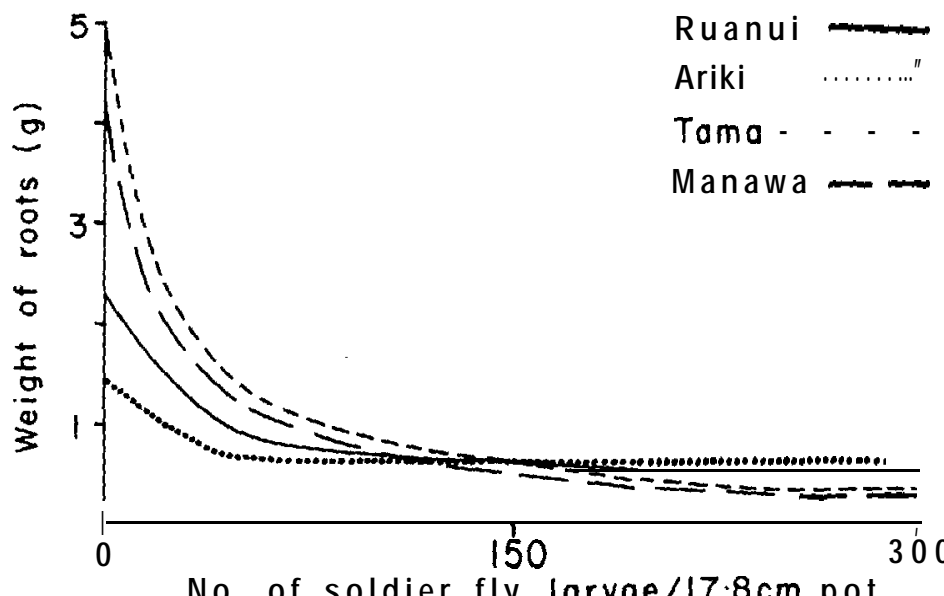

Fig. 1: Relationship between ryegrass roof weights and soldier fly larval population.
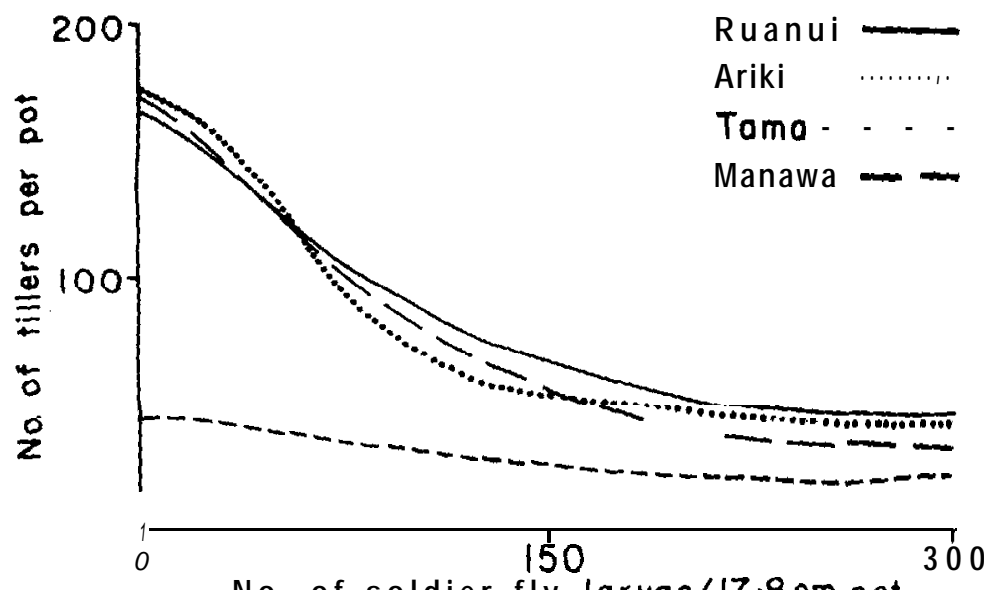

No. of soldier fly larvae $/ 17.8 \mathrm{~cm}$ pot

FIG. 2: Relationship between filler production and soldier fly larval population.

however, there was a suggestion that fewer plants survived at high infestations $(\mathrm{P}<0.10)$.

\section{Tiller Production}

Soldier fly larvae suck sap from the roots close to the soil surface, thereby reducing the. supply of nutrients passing to the 
root system., This was reflected by a lack of tillering, an effect that increased with an increasing larval population (Fig. 2). Tama produced fewer tillers than other varieties in the absence of larvae and was not as seriously affected as other varieties $(P<0.01)$;

\section{WEIGHT OF FOLIAGE}

As a consequence of sap removal from the root, foliage production also dropped markedly with increasing soldier fly infestation (Fig. 3). No difference between varieties was observed.

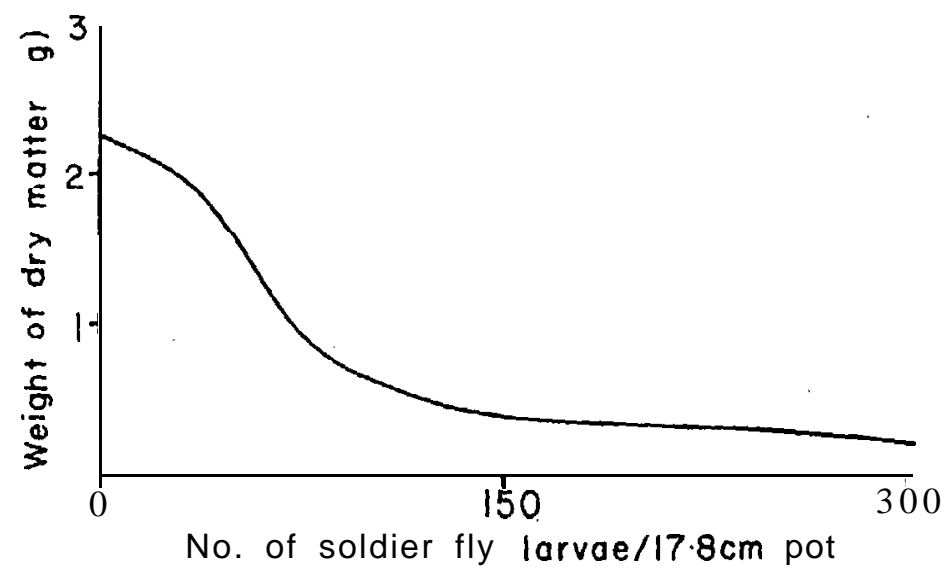

FIG. 3: Relationship between foliage (DM) production and soldier fly larval population.

Over the three months the severity of damage at the high larval infestations increased. The regression coefficients for months 1 to 3 (adjusted for mean production levels and using square root transformation throughout) were $-0.033,-0.048$ and -0.063 , respectively (significantly different $P<0.05$ ).

\section{LaRVAL SuRViVAL}

At larval densities of up to 300 larvae pkr pot, there was no density-related mortality (Table 2) but above this level there was significant mortality; presumably because competition for food became intense.

\section{ENHANCING THE ESTABLISHMENT OF RYEGRASS SEEDLINGS}

A factorially designed field experiment was established at Matangi during autumn 1974 using four replicates in randomized 
RYEGRASS AND SOLDIER FLY

TABLE 2: LARVAL SURVIVAL AT FIVE LARVAL DENSITIES

\begin{tabular}{cc}
\hline No. Larvae/Pot & \% Surviving after 3 Months \\
\hline 38 & $60.5 \mathrm{ABb}$ \\
75 & $70.5 \mathrm{Aa}$ \\
150 & $70.5 \mathrm{Aa}$ \\
300 & $69.5 \mathrm{Aab}$ \\
600 & $49.0 \mathrm{Bc}$. \\
\hline
\end{tabular}

Duncan's Multiple Range Test: means without a common letter differ significantly (lower case, $P<0.05$; capitals, $P<0.01$ ).

blacks. Main factors were with or without insecticide, minimum cultivation or paraquat, drilled or broadcast fertilizer (serpentine superphosphate). Two additional treatments - six weeks' cultivation (discing once a week for six weeks commencing at the onset of the flight period, the first week of March), and untreated areas - were included, giving a total of ten treatments.

The experimental area was grazed hard prior to the flight period when the experiment was laid down. This may have reduced some treatment differences $-\mathfrak{c}$.g., if the untreated pasture had remained long, more eggs may have been laid in this treatment. Minimum cultivation consisted of initial discing followed by $a$ harrowing and final preparation for a seed-bed all within nins days (all plots sown with a mixture of $15 \mathrm{~kg}$ Ruanui and $5 \mathrm{~kg}$ Ariki $/ \mathrm{kg}$, April S-9). Plots treated with paraquat were sown using a triple disc drill, and a coulter drill was used in cultivated plots. Fertilizer was applied using the seed drill, or, where broadcast, using a fertilizer spreader. The insecticide used was carbofuran applied as a seed dressing at $10 \% \mathrm{w} / \mathrm{w}$ seed as a $75 \%$ wettable powder (equivalent to $1.5 \mathrm{~kg}$ active ingredient/ha).

\section{IMPROVING EFFICIENCY OF INSECTICIDE}

Assessments were made of larval numbers in October. The grass was in rows $15 \mathrm{~cm}$ apart and ten $7.5 \mathrm{~cm}$ diameter cores were taken both on and in between the rows per plot.

The number of larvae present was reduced by insecticide and minimum cultivation (Table 3 ). The significant interactions in Table 3 show that:.

(1) Larvae moved on to the rows and were killed by insecticide.

(2) A greater proportion of larvae moved on to the rows in the paraquat treatments than where minimum cultivation was used. This may be because the extra consolidation asso- 
ciated with the paraquat treatment produced larger roots (see Table 4) and these attracted more larvae.

(3) The drilling of fertilizer with the seed also enhanced movement on to the rows as compared with broadcasting fertilizer.

Point analysis results indicated that larvae responded to the presence of ryegrass and bare ground (Table 3).

\section{ESTABLISHMENT OF RYEGRASS SEEDLINGS}

Twelve weeks after sowing assessments were made of the number of plants, root weights and number of larvae in four $20 \mathrm{~cm}$ lengths of row/plot (Table 4).

The number of larvae per plant was lower in the insecticide and minimum cultivation treatments. This reduction by the insecticide was associated with an increase in root weight. However,

TABLE 3: EFFECT OF LARVAL MOVEMENT

(Values are number of 'larvae thousands $/ \mathrm{m}^{2}$ )

\begin{tabular}{|c|c|c|c|c|c|c|}
\hline \multirow{2}{*}{$+\rightarrow+1$} & & & \multicolumn{2}{|r|}{$\mathrm{On}$} & \multirow{2}{*}{$\begin{array}{c}\text { In } \\
\text { Between }\end{array}$} & \multirow[b]{2}{*}{ Mean } \\
\hline & & & & Grass Rows & & \\
\hline No insecticide & $\ldots$ & $\ldots$ & $\ldots$ & $" 2.12$ & 0.63 & $1.38 \mathrm{Aa}$ \\
\hline Insecticide & $\ldots$ & $\ldots$ & A, & '0.83 & 0.68 & $0.75 \mathrm{Bb}$ \\
\hline Min. cultivation & $\ldots$ & & $\ldots$ & "1.15 & 0.58 & $0.81 \mathrm{Bb}$ \\
\hline Paraquat & . & $\ldots$ & $\ldots$ & 1.81 & 0.73 & $1.27 \mathrm{Aa}$ \\
\hline Broadcast fertilizer & & $\ldots$ & $\ldots$ & $* 1.37$ & 0.73 & $1.06 \mathrm{a}$ \\
\hline Drilled fertilizer & $\ldots$ & & $\ldots$ & 1.59 & 0.58 & $1.09 \mathrm{a}$ \\
\hline Point analysis: & & & & & & \\
\hline$\%$ ryegrass hits & & $\ldots$ & $\ldots$ & $72 \mathrm{Aa}$ & $10 \mathrm{Bb}$ & \\
\hline$\%$ bare ground & hits & $\ldots$ & . & $16 \mathrm{Bb}$ & $55 \mathrm{Aa}$ & \\
\hline
\end{tabular}

"Interactions between main factors and on/in between rows significant $\mathrm{P}<0.01$.

TABLE 4: ESTABLISHMENT OF RYEGRASS AND SUBSEQUENT PASTURE PRODUCTION

\begin{tabular}{|c|c|c|c|c|}
\hline & $\begin{array}{l}\text { Plants/ } \\
m \text { of Row }\end{array}$ & $\begin{array}{c}\text { No. } \\
\text { Larvae/Plant }\end{array}$ & $\begin{array}{l}\text { Dry wt of Root/ } \\
\text { Plant }(g)\end{array}$ & $\begin{array}{c}\text { Pasture } \\
\text { Production } \\
(\text { kg } D M / h a) \\
\text { Mar. 1.Oct. } 22\end{array}$ \\
\hline No insecticide & $117 \mathrm{a}$ & $0.96 \mathrm{Aa}$ & $2.9 \mathrm{Bb}$ & $2894 \mathrm{Bb}$ \\
\hline Insecticide & $105 \mathrm{a}$ & $0.27 . \mathrm{Bb}$ & $3.9 \mathrm{Aa}$ & $3302 \mathrm{Aa}$ \\
\hline Min. cultivation & $113 \mathrm{a}$ & $0.50 \mathrm{Bb}$ & $3.0 \mathrm{Bb}$ & $2993 \mathrm{Bb}$ \\
\hline Paraquat & $108 a$ & $0.73 \mathrm{Aa}$ & $3.8 \mathbf{A a}$ & $3203 \mathrm{Aa}$ \\
\hline Broadcast fertilizer & $114 a$ & $0.63 \mathrm{a}$ & $3.5 \mathrm{a}$ & $2975 \mathrm{Bb}$ \\
\hline Drilled fertilizer & $108 \mathrm{a}$ & $0.60 \mathrm{a}$ & $3.3 \mathrm{a}$ & $3221 \mathrm{Aa}$ \\
\hline
\end{tabular}


the minimum cultivation had smaller roots than the paraquat treatment, an effect probably resulting from poorer consolidation in this treatment. Similar effects were observed for pasture production which was greater in the insecticide and paraquat treatments than in the non-insecticide and minimum cultivation treatments.

The better treatments reduced the number of larvae and significantly increased the ryegrass component compared with the untreated sward (Table 5). The untreated sward produced as much as the best treatments over autumn and winter as it was in production during the autumn flush period when treatments were being applied. Obviously these treatments produced more than the untreated over the winter-early spring period. Treatments without soldier fly control measures were disadvantageous as the young seedlings (the only food source for the larvae) were not protected from larval depredations.

\section{DISCUSSION}

The decision to undersow a pasture in the autumn is often based on an assessment of the amount of ryegrass present and how well the pasture is producing.

Hard grazing is considered to be an essential element in undersowing a paddock as this enables easy access for the drill and reduces competition from existing vegetation against establishing seedlings. If correctly timed (last fortnight in March), it may kill soldier fly pupae (Osborn and Forteath, 1974) and reduce both the number of eggs being laid and the survival of any eggs that are laid (Wilcocks and Hewitt, 1971; Kain and Burton, 1975; Hitchcock, 1975). Even after this, however, the number of larvae remaining is likely to be high enough to reduce the vigour of seedlings and the inclusion of a cheap and effective insecticide would be well justified. The degree of control will depend not only upon the rate and effectiveness of the insecticide employed but also upon the extent to which the insecticide is brought into the zone of activity of the larvae, and vice versa. This can be improved by using paraquat or minimum cultivation techniques and drilling fertilizer with the seed.

Accurate placement of the insecticide with the seed is essential and it seems desirable to use it in the form of a seed dressing. This would allow use of the seedlings as a bait for the soldier fly larvae, and, if seed were sown with a roller drill into cultivated ground to minimize the distance larvae have to travel, control should prove very effective. 
TABLE 5: SOME INDIVIDUAL TREATMENT EFFECTS

\begin{tabular}{|c|c|c|c|}
\hline & $\begin{array}{c}\text { No. Larvae/ } \\
\left.\text { (thousands } / m^{2}\right)\end{array}$ & $\begin{array}{l}\text { \% Ryegrass } \\
\text { (Herbage } \\
\text { Dissection) } \\
\text { Oct. 22 }\end{array}$ & $\begin{array}{c}\text { Pasture Production } \\
(D M \mathrm{~kg} / \mathrm{ha}) \\
\text { Mar. } 1-0 \mathrm{ct} .22)\end{array}$ \\
\hline Insecticide, min. cultivation, drilled fertilizer & $0.57 \mathrm{~d}$ & 72 ab & $3331 \mathrm{ab}$ \\
\hline Insecticide, min. cultivation, broadcast fertilizer & $0.68 \mathrm{~cd}$ & $63 \mathrm{~b}$ & 3226 abc \\
\hline Six weeks' cultivation, drilled fertilizer & $0.82 \mathrm{dd}$ & 81 a & 3296 ab \\
\hline Insecticide, paraquat, drilled fertilizer & $0.85 \mathrm{c}$ & 75 ab & 3490 a \\
\hline No insecticide, min. cultivation, drilled fertilizer & $1.24 \mathrm{~b}$ & $63 \mathrm{~b}$ & $2971 \mathrm{c}$ \\
\hline Untreated & $1.43 \mathrm{a}$ & 44c & 3321 ab \\
\hline No insecticide, paraquat, drilled fertilizer & 1.69 a & 70 ab & $3093 b c$ \\
\hline
\end{tabular}


Techniques incorporating minimum cultivation or paraquat with insecticide and fertilizer sown with the seed compare favourably with a six weeks' cultivation programme as methods of reducing soldier fly infestations and renovating pasture (Table 5).

It is relevant to note the problems associated with minimum cultivation and use of paraquat. In the former situation very hard grazing is required to reduce the organic matter and enable a seedbed to be formed rapidly. In the latter situation if the pasture contains broad-leaved weeds then these can become dominant, in which case the use of a hormonal weedkiller is essential. If clover. dominant, then enough paraquat must be applied to reduce its growth thereby causing the larvae to move on to the tyegrass seedlings.

This paper has dealt with techniques of complete pasture renovation. For pastures that have high infestations of soldier fly but which still retain a satisfactory balance of species, hard graziag coupled with the undersowing of an insecticide during the autumn flight period (March-April) may prove to be the most satisfactory method of preventing a deterioration of pasture composition and should provide an increase in pasture production (MacKay et al., 1974; Dixon, 1974). More research is in progress to' determine the cost/benefit. ratios of these autumn treatments.

\section{ACKNOWLEDGEMENTS}

Miss E. Witt and Mrs G. Macdonald for technical assistance, C. B. Dyson and biometrics staff at Ruakura for statistical analysis, and W, G. Flower for co-operation and use of land on which the field experiment was conducted.

\section{REFERENCES}

Cumberland, G. L. B.; Dyson, C. B.; Farrell, C. A., 1973. Proc. 26th N.Z. Weed \& Pest Control Conf.: 196.

Cumberland, G. L. B.; Honore, E. N.; Farrell, C. A., 1974. Proc. 27th N.Z. Weed \& Pesf Control Conf.: 222.

Dixon, G. M., 1974. Proc, Ruakura Fmrs' Conf.: 62.

Dixon, G. M.; Dyson, C. B.; Grimmer, D. C., 1974. P I-oc. 27th N.Z. Weed \& Pest Control Conf.: 210.

Hitchcock, B. E., 1975. Bull. ent. Res.: in press.

Kain, W. M.; Burton, G., 1975. Proc. $28 \mathrm{th}$ N.Z. Weed \& Pest Control Conf:: 237.

Mackay, A. G.; Rowe, G. R.; Guthrie, N. C., 1974. Proc. 27th N.z. Weed \& Pest Control Conf.: 215.

Osborn, A. W.; Forteath, G. N. R., 1974. Environmental Ent., 3 (1): 29.

Wilcocks, C. R.; Hewitt, R., 1971. Proc, 24th N.Z. Weed \& Pesf Control Conf.: 160. 